\title{
Agricultural irrigation requirements under future climate scenarios in China
}

\author{
XiuFang ZHU ${ }^{1,2 *}$, AnZhou ZHAO ${ }^{1,2}$, YiZhan LI ${ }^{1,2}$, XianFeng LIU ${ }^{1,2}$ \\ ${ }^{1}$ State Key Laboratory of Earth Surface Processes and Resource Ecology, Beijing Normal University, Beijing100875, China; \\ ${ }^{2}$ College of Resources Science and Technology, Beijing Normal University, Beijing100875, China
}

\begin{abstract}
Projecting future water demand, especially in terms of agricultural irrigation demand, as well as identifying high-risk areas and establishing appropriate water demand management has become increasingly important in China. Climate scenarios provide opportunities to predict future irrigation requirements (IRs). We examined changes in IRs and agricultural drought in response to rising greenhouse gas concentrations in China using eight global climate models from the Intergovernmental Panel on Climate Change Fourth Assessment Report. In this research, Northeast China, the North China Plain and the Yarlung Tsangpo River Valley area in southeastern Tibet were estimated to receive more precipitation in the future, whereas Southeast and Northwest China, especially the Junggar and Tarim basins in Xinjiang Uygur autonomous region, will receive less precipitation. IRs will undergo a significant increase in summer (June-August), especially in July, whereas the smallest increase was predicted to occur in autumn (September-November). Middle rice was identified as the greatest contributor to the increase in total IRs. The areas predicted to experience significant increases in IRs include Northwest China (the Tarim and Junggar basins in Xinjiang Uygur autonomous region, the Hexi Corridor in Gansu province and the Guanzhong Plain in Shaanxi province), Southeast China (especially Fujian province), and Southwest China (Yarlung Tsangpo River Valley area in Tibet and the Sichuan Basin).
\end{abstract}

Keywords: agricultural drought; water demand; agricultural irrigation requirement; climate change; IPCC scenarios

Citation: XiuFang ZHU, AnZhou ZHAO, YiZhan LI, XianFeng LIU. 2015. Agricultural irrigation requirements under future climate scenarios in China. Journal of Arid Land, 7(2): 224-237. doi: 10.1007/s40333-014-0080-y

China, the most populous country in the world, constantly faces challenges in terms of food security. The country has less than $10 \%$ of the world's arable land to feed its 1.3 billion people (Wu et al., 2010). Arable land and available water resources are unevenly distributed in China. To realize self-sufficiency in food production, the Chinese have undertaken large scale programs to increase agricultural production, such as using chemical pesticides and fertilizers, developing new strains of genetically modified crops, and investing in irrigation infrastructure. Among these measures, agricultural irrigation is the largest contributor to crop yield increase and poverty reduction in rural areas (Huang et al., 2006).

Agricultural irrigation is expected to continue to contribute to the stabilization of food prices, as well as to the increase in farmers' incomes and food supply to the Chinese society. However, development of additional water resources and infrastructure in the future may be limited. Water security is a major concern in various sectors. In addition, climate change is estimated to worsen the situation; global warming is expected to continue, which is likely to accelerate evaporation and soil dryness (Sheffield and Wood, 2008). Climate change also spatially and temporally modifies precipitation, placing more stress on the water and food security of China (Kitoh et al., 2005; Zhang et al., 2006; Kharin et al., 2007; Chen and Sun, 2009). Therefore, projecting future water demand, particularly agricultural irrigation demand, as well as

*Corresponding author: XiuFang ZHU (E-mail: zhuxiufang@bnu.edu.cn)

Received 2013-12-31; revised 2014-03-04; accepted 2014-05-12

(C) Xinjiang Institute of Ecology and Geography, Chinese Academy of Sciences, Science Press and Springer-Verlag Berlin Heidelberg 2015 
identifying high-risk areas and establishing appropriate water demand management schemes is imperative.

Numerous reports have described the impact of climate change on agricultural production in China (Tao et al., 2003, 2008; Liu et al., 2004; Lin et al., 2005; Xiong et al., 2007a, b; Yao et al., 2007; Chavas et al., 2009; Mo et al., 2009; Tao et al., 2009; Xiong et al., 2009; Guo et al., 2010; Liu et al., 2010; Tao and Zhang, 2011); however, studies examining its effect on irrigation water requirements are limited (Doll, 2002; Rosenzweig et al., 2004; Cai, 2005; Thomas, 2008; Rockstrom et al., 2009). Climate change scenarios provide opportunities to project future irrigation requirements (IRs), although large uncertainties have been reported in the currently developed general circulation models (Wang, 2004).

In this study, we analyzed the changes in IRs and agricultural drought in response to rising greenhouse gas concentrations in China. We utilized eight global climate models from the Intergovernmental Panel on Climate Change Fourth Assessment Report (IPCC 4), and the analysis is based on multiple-model averages of climate differences between 1961 and 2000 simulations and the simulation of three scenarios. We addressed the following questions: (1) How will IRs change temporally and spatially in the cropland of China in the future? (2) Which, among the three main grain crops (wheat, corn and rice) planted in China, will demonstrate the biggest irrigation requirement change? and (3) What are the areas at risk for the largest IR increase? The answers to these questions can help identify areas of potentially high IRs and at high-risk for drought, as well as facilitate the development of appropriate adaptations and strategies to mitigate water scarcity.

\section{Materials and methods}

\subsection{Cropping pattern and growing season}

Three main crops (wheat, corn and rice) were selected for estimating IRs in the Chinese mainland (Hong Kong, Macao and Taiwan are excluded from this study due to data unavailability.). Paddy rice includes early, middle and late rice, grown mainly in the Yangtze River Valley, South China and on the Yunnan-Guizhou Plateau; wheat includes spring and winter wheat, planted mainly on the North China Plain; and corn includes spring and summer corn, planted mainly in the northeastern, northern, and southwestern China. According to the China Statistical Yearbook 2009 (NSBC, 2010), the total sown area of grain crops was 106.8 million $\mathrm{hm}^{2}$ in 2008, of which those of rice, wheat and corn comprised $77.5 \%$. Rice, wheat and corn outputs accounted for $36.2 \%, 21.3 \%$ and $31.4 \%$ of the total grain output $\left(528.7 \times 10^{6}\right.$ tons $)$, respectively.

The cropping systems, planting dates and harvest dates for each of these crops in each region have been reported online by the Chinese government since 2000 (http://www.zzys.gov.cn; accessed at 12 September 2011). The planting and harvest dates of each crop during the past decade were quite stable. The average planting dates and harvest dates of rice, wheat and corn from 2000 to 2008 were calculated for each region.

\subsection{Climate data}

Data of daily precipitation (Pr), downwelling shortwave radiation (DSR) and mean air temperature (T) during 1961-2000 were obtained from the Climate of the $20^{\text {th }}$ Century Experiment of the IPCC 4 . The Pr, DSR and $\mathrm{T}$ during the future time period of 20462065 were derived from three IPCC 4 scenarios (B1, $\mathrm{A} 1 \mathrm{~B}$ and A2). Scenario A1 assumes that economic growth rapidly occurs with the introduction of new and more efficient technologies and that the global population will peak in the middle of the $21^{\text {st }}$ century. $\mathrm{A} 1$ is divided into three groups (A1FI, A1T and A1B) based on the alternative directions of technological change. A1FI refers to fossil intensive, A1T refers to non-fissile energy resources, and A1B is a balance of all sources. Scenario B1 assumes a convergent world, and, similar to A1, it assumes that the global population will peak in the middle of the $21^{\text {st }}$ century but that the economic structure changes rapidly to a service and information economy. Scenario A2 describes a very heterogeneous world. Under this scenario, population growth is high, and economic development and technological change are slow (Pachauri and Reisinger, 2007). All data were downloaded from the WCRP CMIP3 multi-model database (https://esg.llnl.gov:8443/home/publicHome Page.do). A total of 24 models were included in IPCC 4. Our study uses the results from eight of those 
models (Table 1). All eight models provide daily data over the same time periods and are interpolated to $0.5^{\circ}$ latitude/longitude because the data from the different models have various spatial resolutions.

Table 1 Climate change models used in this study

\begin{tabular}{ccccc}
\hline No. & Model name & $\begin{array}{c}\text { Short } \\
\text { name }\end{array}$ & Country & $\begin{array}{c}\text { Resolution } \\
\text { (degree) }\end{array}$ \\
\hline 1 & cccma_cgcm3_1 & CGMR & Canada & $3.75 \times 3.71$ \\
2 & cnrm_cm3 & CNCM3 & France & $2.81 \times 2.79$ \\
3 & csiro_mk3_0 & CSMK30 & Australia & $1.88 \times 1.87$ \\
4 & csiro_mk3_5 & CSMK35 & Australia & $1.88 \times 1.87$ \\
5 & gfd1_cm2_0 & GFCM20 & USA & $2.50 \times 2.00$ \\
6 & gfd1_cm2_1 & GFCM21 & USA & $2.50 \times 2.00$ \\
7 & miroc3_2_medres & MIMR & Japan & $2.81 \times 2.79$ \\
8 & mri_cgcm2_3_2a & MRCGCM & Japan & $2.81 \times 2.79$ \\
\hline
\end{tabular}

\subsection{Net IRs and drought index}

In our study, the net IRs per unit during the growing season was computed as the difference between crop-specific potential evapotranspiration (PET) and effective precipitation (Peff) (FAO, 1992). PET was calculated using the Hargreaves and Samani function (Hargreaves and Samani, 1982). Aridity index (AI) was calculated from the mean annual precipitation and PET using a method proposed by the United Nations Environment Program (UNEP, 1997) .

$$
\begin{array}{ll}
\mathrm{PET}=0.0135 \times(\mathrm{T}+17.8) \times \mathrm{DSR} / \lambda, \\
\mathrm{IR}_{\text {net }}=\mathrm{Kc} \times \mathrm{PET}-\mathrm{Peff}, & \text { if } \mathrm{Kc} \times \mathrm{PET}>\mathrm{Peff} \\
\mathrm{IR}_{\text {net }}=0 & \text { otherwise, } \\
\mathrm{Peff}=\operatorname{Pr}(4.17-0.2 \mathrm{Pr}) / 4.17, & \text { for } \operatorname{Pr}<8.3 \mathrm{~mm} / \mathrm{d} ; \\
\mathrm{Peff}=4.17+0.1 \mathrm{Pr}, & \text { for } \operatorname{Pr} \geqslant 8.3 \mathrm{~mm} / \mathrm{d} ; \\
\mathrm{AI}=\operatorname{Pr} / \mathrm{PET} . &
\end{array}
$$

Where, PET is the potential evapotranspiration $(\mathrm{mm} / \mathrm{d})$; $\mathrm{T}$ is air temperature $\left({ }^{\circ} \mathrm{C}\right) ; \lambda$ is latent heat of vaporization $(2.45 \mathrm{MJ} / \mathrm{kg})$; DSR is the downwelling shortwave radiation $\left(\mathrm{MJ} /\left(\mathrm{m}^{2} \cdot \mathrm{d}\right)\right)$; $\mathrm{Pr}$ is the daily total precipitation $(\mathrm{mm} / \mathrm{d})$; Peff is the fraction of $\operatorname{Pr}$ available to the crop and called effective precipitation $(\mathrm{mm} / \mathrm{d}) ; \mathrm{Kc}$ is a crop coefficient (dimensionless), which is a function of the crop type and the days of the growing season (Table 2); and $\mathrm{AI}$ is the aridity index.

\section{Results}

The IRs of a crop were affected not only by the amount but also by the timing of Pr and evapotranspiration. In
Table 2 Lengths of crop stages and crop coefficients as a fraction of the whole growing season

\begin{tabular}{cccccccccc}
\hline Crop & \multicolumn{3}{c}{ Length of crop development stage } & & \multicolumn{3}{c}{ Crop coefficients } \\
\cline { 1 - 2 } & L_ini & L_dev & L_mid & L_late & & kc_ini & kc_mid & kc_late \\
\hline Wheat & 0.15 & 0.25 & 0.40 & 0.20 & & 0.40 & 1.15 & 0.30 \\
Corn & 0.17 & 0.28 & 0.33 & 0.22 & & 0.30 & 1.20 & 0.40 \\
Rice & 0.17 & 0.18 & 0.44 & 0.21 & & 1.05 & 1.20 & 0.75 \\
\hline
\end{tabular}

Note: Lengths of crop stages for initial period (L_ini), crop development (L_dev), mid (L_mid) and late (L_late), crop coefficients for initial period (kc_ini), mid (kc_mid) and end (kc_end) (Siebert and Döll, 2008).

this study, we analyzed spatial and temporal changes in climate and IRs. Through spatial analysis, we identified the high-risk areas that have higher increases in IR and drought tendencies. Through temporal analysis, we explored the seasonal changes in IRs, which would guide in the optimization of irrigation scheduling and water quota management. We also analyzed the changes in the IRs for rice, corn and wheat, which can facilitate the design of water management practices such as adjusting crop distribution and structure.

\subsection{Spatial analysis of changes in climate and IRs in the entire cropland of China}

The changes in climate and IRs for the future time period of 2046-2065 were shown in Fig. 1. Under scenario B1 and A1B, DSR was shown to increase in Southeast China as well as in the Junggar Basin of Xinjiang Uygur autonomous region, whereas it would decrease in the rest of the country. Under scenario A2, DSR decreased in entire China except for the area west of the Junggar Basin.

$\mathrm{T}$ is estimated to increase in entire China under all three scenarios, whereas it will increase most under scenario A1B. Under scenario B1, T would increase by $1.0-1.5 \mathrm{~K}$ in most parts of China, whereas Southwest and Northwest China will show a higher increase $(1.5-2.0 \mathrm{~K})$. Under scenario A1B, T would increase by $1.5-3.5 \mathrm{~K}$, and the largest increase would occur in the northeastern, northwestern and southwestern regions of China. Under scenario A2, the highest increase would occur in the Northeast and Southwest China, and the smallest increase would occur in Jiangsu, Anhui, Guangdong and Hainan provinces.

Under all three scenarios, PET would increase 

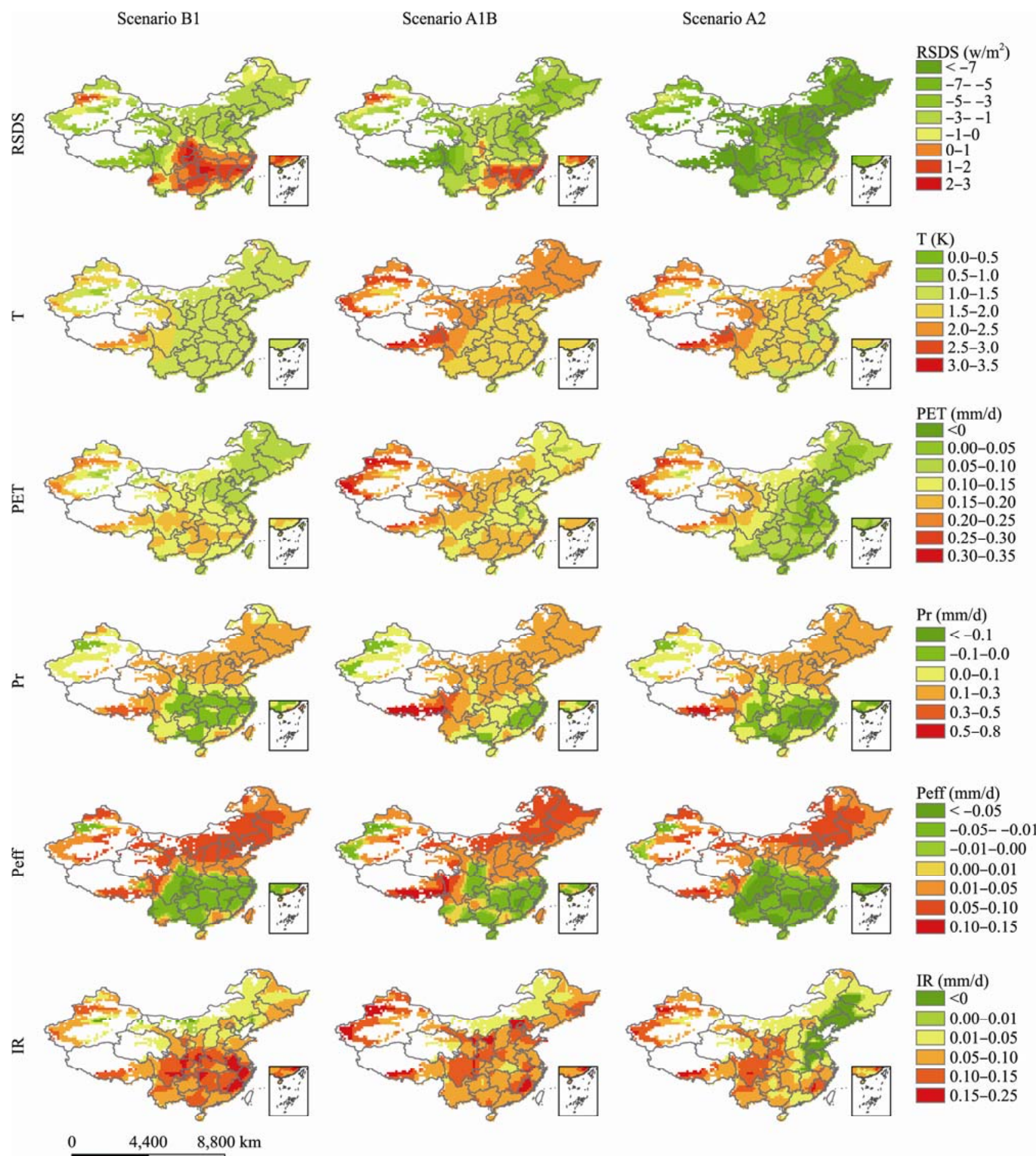

Fig. 1 Changes in climate and irrigation requirements (IRs) in the cropland of China during 2046-2065 under three scenarios. Peff, effective precipitation; PET, potential evapotranspiration; Pr, precipitation; DSR, downwelling shortwave radiation; T, air temperature.

throughout China, with Northeast China and the North China Plain undergoing a smaller increase. Pr will increase in most regions of China, especially in the Yarlung Tsangpo River Valley area, whereas it will decrease in Southeast China along the Yangtze River and in the Junggar Basin of the Xinjiang Uygur autonomous region. Peff will increase in most areas of China, especially in the Songliao Basin of Northeast China, the Erlian Basin of Inner Mongolia autonomous region, and the Yarlung Tsangpo River 
Valley area, and will decrease in the Yangtze River Basin and the Sichuan Basin.

IRs are predicted to increase in most regions of China, especially in Northwest China (such as the Tarim and Junggar basins, the Hexi Corridor of Gansu province and the Guanzhong Plain of Shaanxi province), Southeast China and Southwest China (such as the Sichuan Basin and the Yarlung Tsangpo River Valley area). Inner Mongolia autonomous region will undergo the smallest increase in IR. Under scenario A2, the IRs of part of the North China Plain and Northeast China are estimated to decrease slightly because the increase in PET will offset elevations in Peff in those areas.

The climate is defined as arid when $\mathrm{AI}$ is lower than 0.2, semi-arid when $\mathrm{AI}$ is between 0.2 and 0.5 , dry subhumid when $\mathrm{AI}$ is between 0.5 and 0.65 , and humid when $\mathrm{AI}$ is greater than 0.65 (UNEP, 1997). AI was calculated for the baseline period (1961-2000) and for the two future time periods for all the three scenarios, and data were then compared. The results are shown in Fig. 2. A higher AI is strongly associated with a wetter climate; therefore, if the future AI increases by $5 \%-10 \%$ compared to the baseline AI, then we record it as " $+(5 \%-10 \%)$ " in the figure, which means the future climate will be $5 \%-10 \%$ wetter than that in the baseline period. Northeast China, the North China Plain, and the Yarlung Tsangpo River Valley area in southeastern Tibet are estimated to be wetter in the future (Fig. 2), whereas Southeast and Northwest China, especially the Junggar and Tarim basins in the Xinjiang Uygur autonomous region, will be drier in the future.

\subsection{Temporal analysis of changes in climate and IRs in the entire cropland of China}

DSR, T, Pr, Peff and IR under three scenarios from the baseline period (1961-2000) to the period of 2046-2065 are changed (Fig. 3). The dotted lines show the daily mean value in a given year from each model used in this study, the black solid lines indicate the average daily mean values from the eight models, the bars show the difference in the average daily mean value from the eight models compared to the baseline values, the red solid lines are from the linear regression analyses of the difference, and a is the
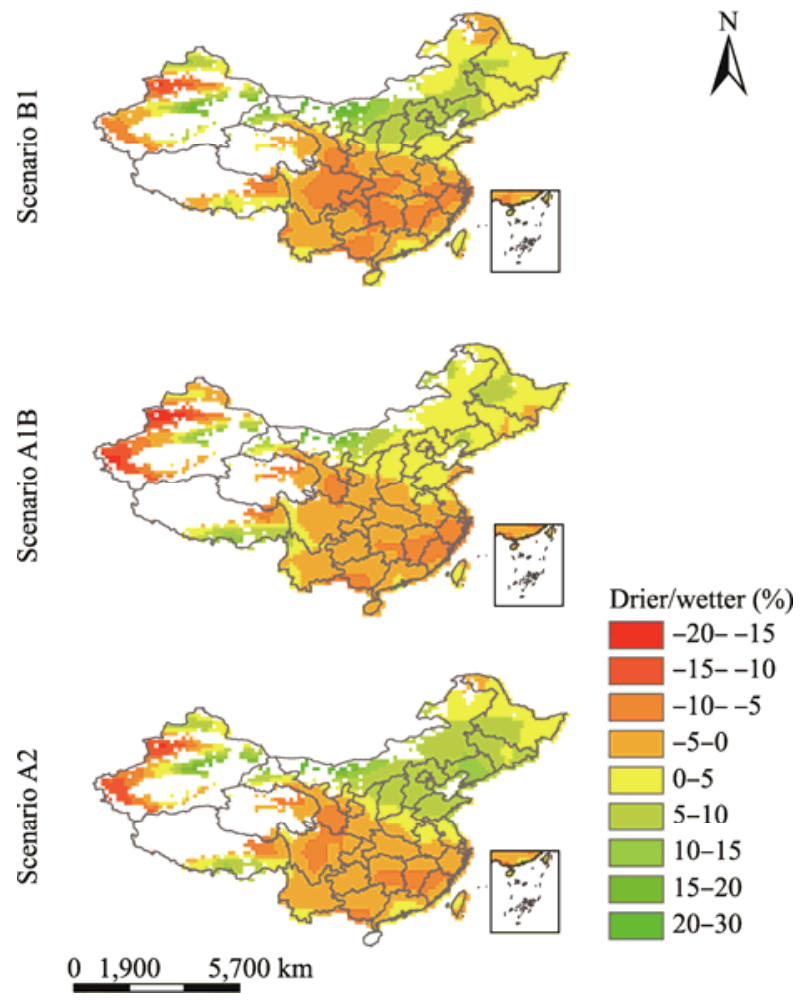

Fig. 2 Comparison of Al between the baseline period (19612000) and the time periods of 2046-2065 and 2081-2100 under three scenarios ("+" denotes a wetter future climate compared to the baseline; "-" denotes a drier future climate compared to the baseline)

linear regression coefficient. Baseline values are the average daily means from the eight models during the time period of 1961-2000.

The mean daily DSR is estimated to generally decrease and the mean daily T, PET, Pr, Peff and IR are estimated to generally increase during 2046- 2065. Table 3 shows the changes in climate and IRs of each season between the baseline and the time period of 2046-2065 under three scenarios. The baseline values were calculated by averaging the monthly means of the output of each season from the eight models used in this study for 1961-2100. Figure 4 shows the details for each month. Under all the three scenarios, IR, Peff, Pr, PET and T increased throughout the year, although the extent of increase differs from month to month. DSR undergoes the most significant decrease in spring and the least significant decrease in summer; $\mathrm{T}$ will show the greatest increases in winter, whereas the largest increases in 

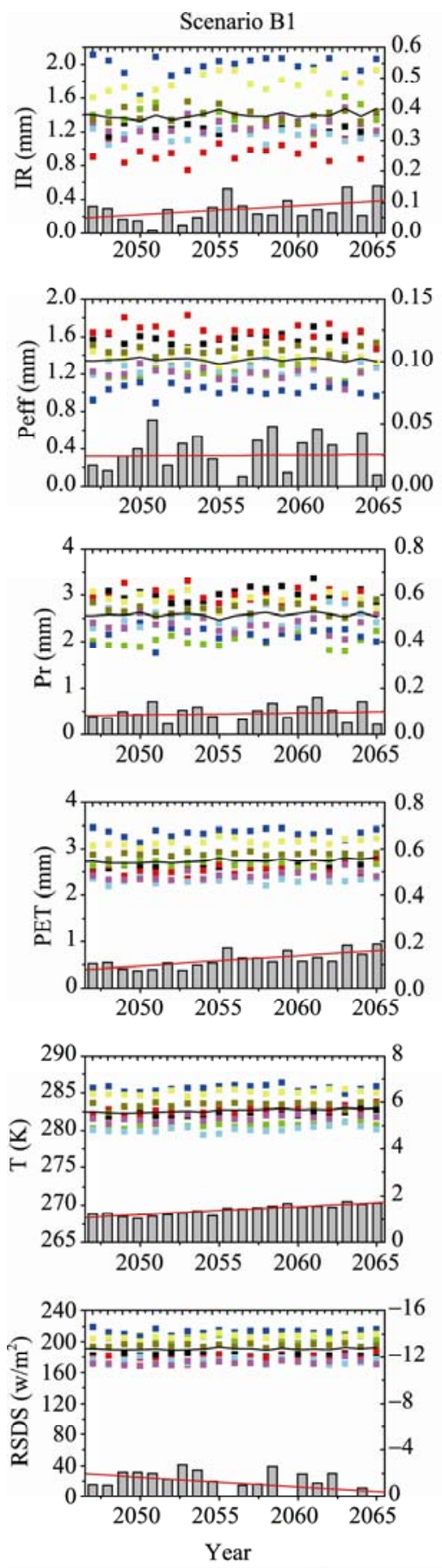

accma_cgcm3_1 $\quad$ cnrm_cm3 gfdl_cm2_1
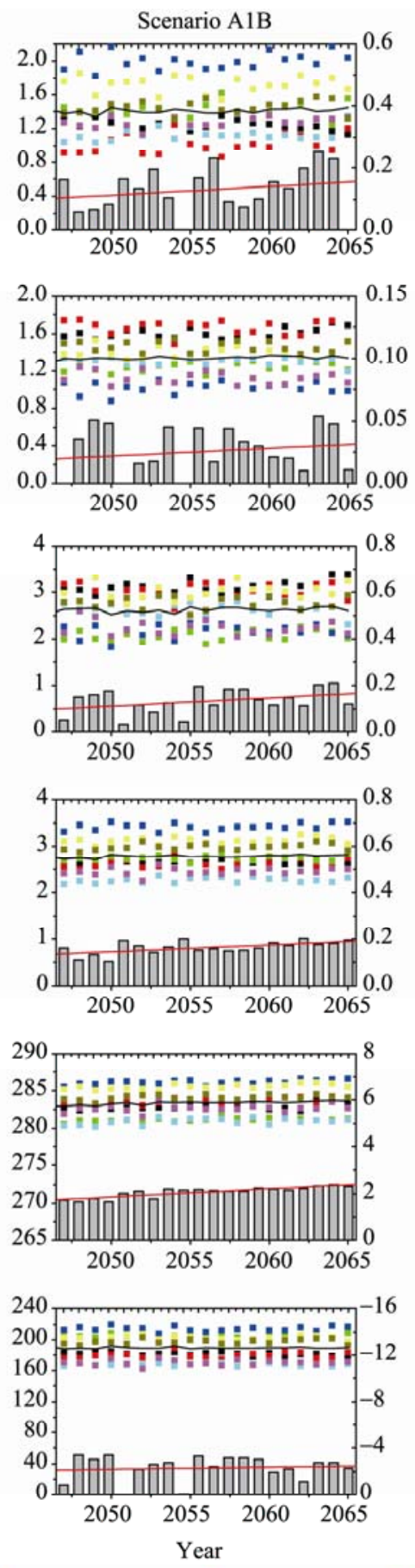
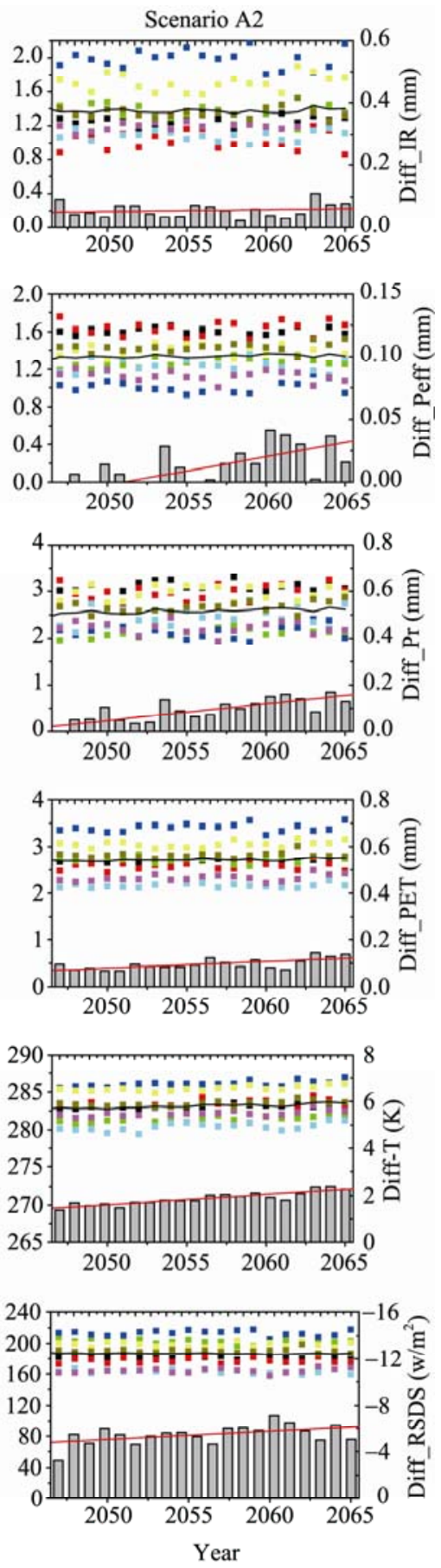

Fig. 3 Predicted daily mean irrigation requirement (IR), effective precipitation (Peff), precipitation (Pr), potential evapotranspiration (PET), air temperature (T) and downward shortwave radiation (DSR) during 2046-2065 under three scenarios and their differences from the baseline period (1961-2000)

PET would occur in summer. The largest increases in Pr would occur in summer, whereas the most significant increases in Peff would occur in spring.
These trends indicate that extreme rain will occur more frequently in future summers. Overall, the greatest increases in IRs would occur in summer (June-August), 
especially in July, whereas the smallest increases would occur in autumn (September-November).

Table 3 Changes in climate and irrigation requirements (IRs) in each season during the studied periods under three scenarios

\begin{tabular}{|c|c|c|c|c|c|}
\hline \multirow{2}{*}{ Variable } & \multirow{2}{*}{ Season } & \multirow{2}{*}{$\begin{array}{c}\text { Baseline } \\
(1961-2000)\end{array}$} & \multicolumn{3}{|c|}{ Change during 2046-2065 } \\
\hline & & & B1 & $\mathrm{A} 1 \mathrm{~B}$ & A2 \\
\hline \multirow{4}{*}{ PET (mm) } & Winter & 31.76 & 6.76 & 10.77 & 7.43 \\
\hline & Spring & 92.25 & 12.12 & 17.94 & 12.31 \\
\hline & Summer & 132.50 & 16.30 & 18.71 & 9.75 \\
\hline & Autumn & 64.56 & 8.92 & 11.89 & 5.48 \\
\hline \multirow{4}{*}{$\operatorname{DSR}\left(w / m^{2}\right)$} & Winter & 134.60 & -4.90 & -5.77 & -12.99 \\
\hline & Spring & 231.85 & -6.63 & -9.76 & -18.95 \\
\hline & Summer & 237.31 & 1.75 & -5.01 & -16.80 \\
\hline & Autumn & 161.56 & -4.34 & -7.39 & -17.07 \\
\hline \multirow{4}{*}{$\mathrm{T}(\mathrm{K})$} & Winter & 270.59 & 4.45 & 6.84 & 6.21 \\
\hline & Spring & 281.87 & 3.99 & 6.03 & 5.56 \\
\hline & Summer & 293.23 & 4.19 & 6.00 & 5.40 \\
\hline & Autumn & 281.34 & 4.25 & 6.14 & 5.45 \\
\hline \multirow{4}{*}{$\operatorname{Pr}(\mathrm{mm})$} & Winter & 27.14 & 3.89 & 0.86 & 1.89 \\
\hline & Spring & 80.91 & 12.90 & 16.20 & 9.56 \\
\hline & Summer & 139.60 & 10.46 & 24.84 & 16.31 \\
\hline & Autumn & 56.36 & 5.43 & 6.78 & 5.42 \\
\hline \multirow{4}{*}{$\mathrm{P}_{\text {eff }}(\mathrm{mm})$} & Winter & 18.67 & 2.44 & 0.52 & 1.19 \\
\hline & Spring & 43.99 & 4.29 & 4.01 & 2.00 \\
\hline & Summer & 69.67 & 0.83 & 3.61 & 0.42 \\
\hline & Autumn & 32.18 & 1.58 & 1.37 & 0.54 \\
\hline \multirow{4}{*}{ IR (mm) } & Winter & 20.61 & 5.30 & 8.77 & 6.76 \\
\hline & Spring & 60.65 & 9.33 & 14.70 & 11.29 \\
\hline & Summer & 111.46 & 20.07 & 19.02 & 11.44 \\
\hline & Autumn & 31.44 & 6.10 & 4.65 & 1.19 \\
\hline
\end{tabular}

Note: Winter, Dec-Jan-Feb; Spring, Mar-Apr-May; Summer, Jun-Jul- Aug; Autumn, Sep-Oct-Nov.

\subsection{Changes in IRs for the main crops in China}

Figure 5 shows the IRs and the mean increases in IR of the three main crops in China, and Fig. 6 shows the ratio of the IR increase of each crop to the total IR increase during 2046-2065 under the three scenarios. For all three crops, IR is estimated to be increased in the future under all three scenarios, although the magnitudes of increase may be variable. Under scenario $\mathrm{B} 1$, late rice provides the greatest contribution to the total IR increase, whereas corn provides the least contribution (Fig. 6a). Under scenario $\mathrm{A} 1 \mathrm{~B}$, middle rice shows the highest contribution to the total IR increase, whereas late rice is the least contributor for 2046-2065 (Fig. 6b). Under scenario A2, wheat is the greatest contributor to the total IR increase, whereas late rice is the least contributor during both periods (Fig. 6c).

\section{Discussion}

\subsection{High-risk areas}

Although the changes in IR estimated from three scenarios differ in their details, the general findings indicate that large increases in IR will occur in Northwest, Southeast and Southwest China. In Northwest China, the Tarim and Junggar basins in the Xinjiang Uygur autonomous region, the Hexi Corridor in Gansu province and the Guanzhong Plain in Shaanxi province will experience the most significant change in IRs. Those basins are the major grain-producing areas in Northwest China and have fewer available water resources (Fig. 7). These large IR increases are likely to aggravate water shortage and potentially reduce crop output.

The areas in Southeast China generally have greater increases in IRs owing to both the decrease in Peff and the increase in PET. Rice, which consumes a high amount of water, is the major crop planted in these areas. Moreover, the water use efficiency in Southeast China is lower than the national mean (Fig. 7). Rapid economic growth and urbanization are diverting more and more water from the agricultural sector to the industrial and residential sectors. Therefore, the increases in IRs in Southeast China may still place immense stress on water and food security.

In Southwest China, the Yarlung Tsangpo River Valley area in Tibet and the Sichuan Basin will undergo increases in IRs. The AI shows that the Yarlung Tsangpo River Valley area will be wetter in the future owing to the large increase in precipitation. PET increase will offset the Peff increase, leading to an increase in IR. The Sichuan Basin will be drier in the future owing to the decrease in Peff and the increase in PET. Tibet has the most abundant water resources but the lowest water use efficiency across China (Fig. 7). Sichuan also has abundant water resources, although its water use efficiency is significantly lower than the national mean (Fig. 7). Considering the large volume of available water in these two areas, it is expected that they could easily handle changes in IR, although the risk continues to exist. 

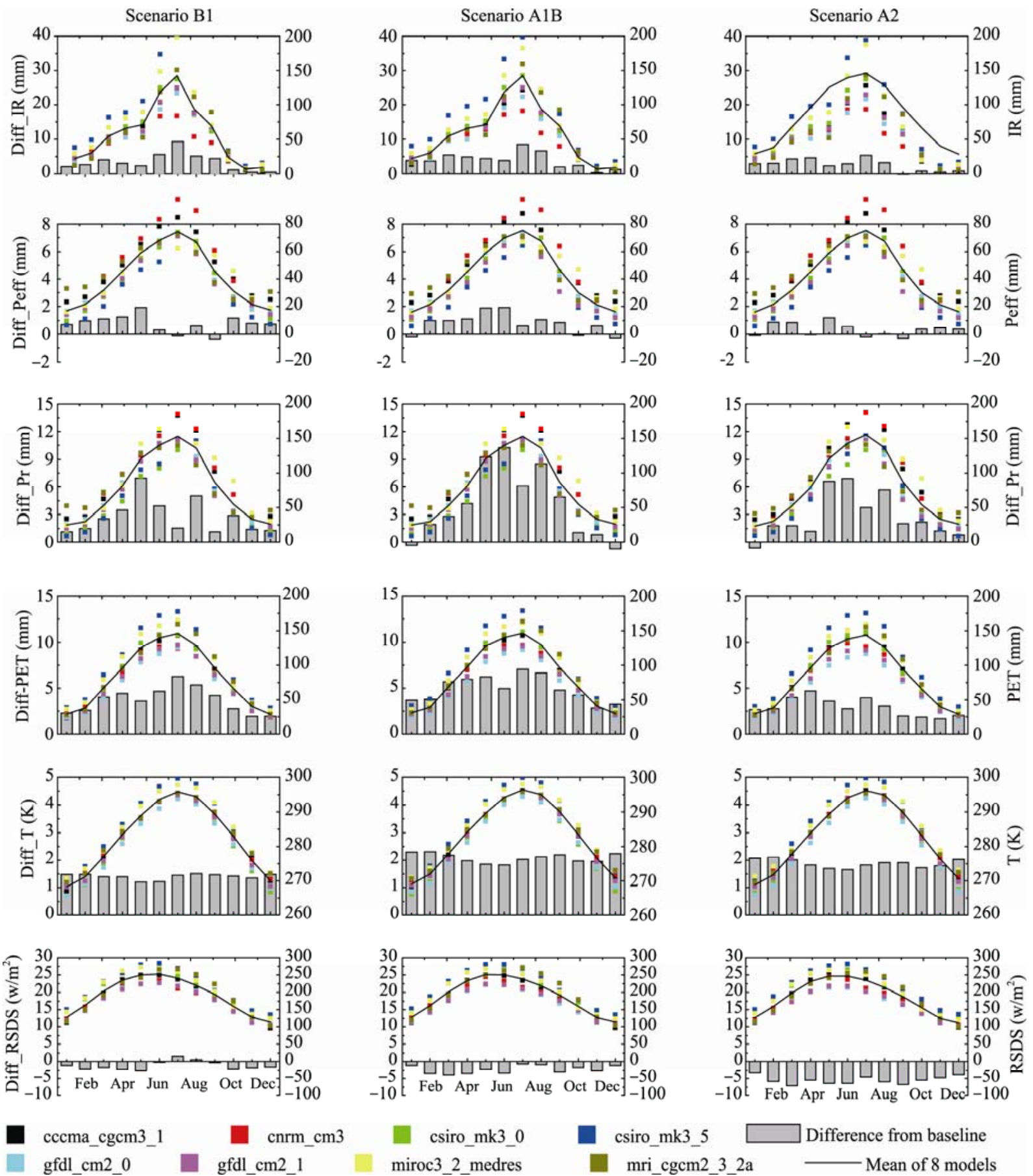
gfdl_cm2_0
gfdl_cm2_1

csiro_mk3_5

mri_cgcm2_3_2a $\square$ Difference from baseline
2a $\quad$ Mean of 8 models

miroc3_2_medres

Fig. 4 Monthly mean irrigation requirements (IRs), effective precipitation (Peff), precipitation (Pr), potential evapotranspiration (PET), temperature (T) and downward shortwave radiation (DSR) for 2046-2065 under three scenarios and their differences from the baseline period (1961-2000)

\subsection{Potential methods adapted to IR and climate changes in the future}

Water use can be divided into domestic, industrial, agricultural and ecological uses. Agricultural use includes water for farmland irrigation, forestry, animal husbandry and fisheries. The water use structure of China is changing along with economic development. More and more water has been diverted to the industrial, ecological, and domestic sectors. The water for farmland irrigation is also shrinking. To achieve 

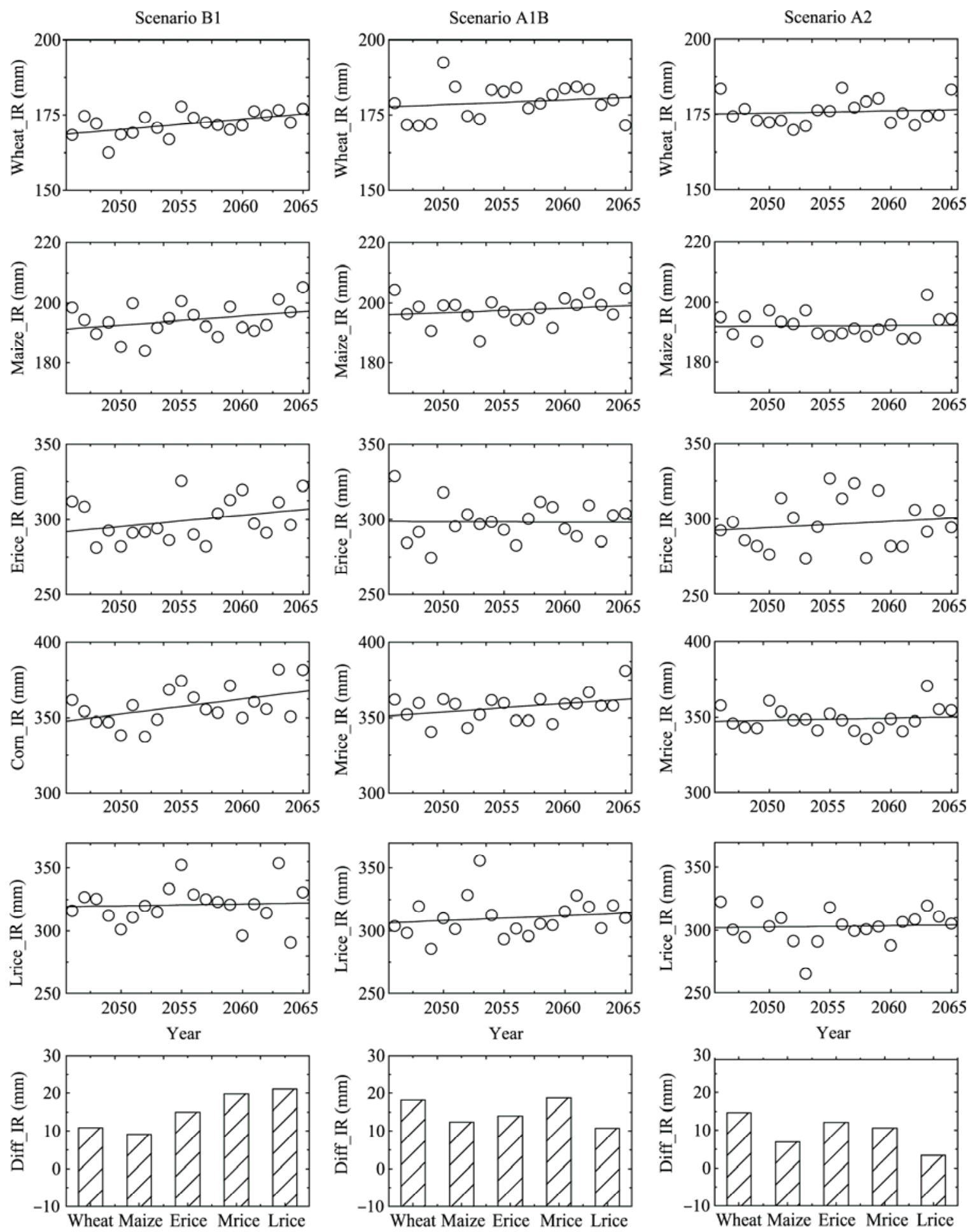

Mean IR estimated from 8 modles

Linear fit of mean IR

$Z Z \triangle$ Mean IR difference between baseline and 2046-2065

Fig. 5 Mean irrigation requirements (IRs) of the main crops of China during 2046-2065 and their changes from baseline (1961-2000). Erice, Mrice and Lrice refer to early rice, middle rice and late rice, respectively. 


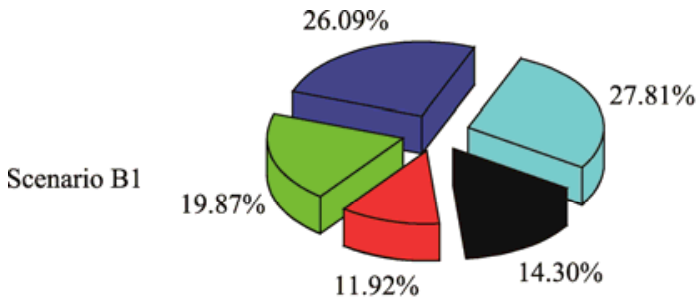

(a)

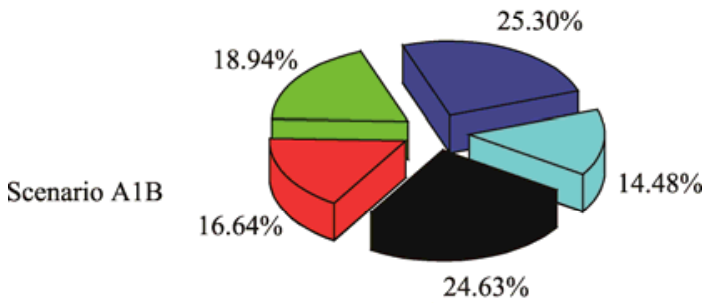

(b)

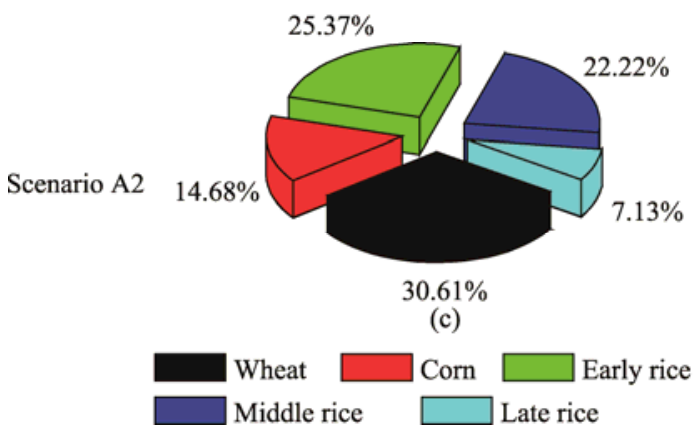

Fig. 6 The ratio of increases in irrigation requirements (IRs) of each crop to the total increase in IRs during 2046-2065 under three scenarios

sustainable economic development and satisfy the increasing needs to supply food for an expanding population, the government must develop appropriate water management strategies to harmonize the water use structure among different sectors as well as within the agricultural sector (Wang and Gao, 2002; Chen et al., 2005; Fang et al., 2007; Wei et al., 2008).

The water use efficiency of irrigation systems is inefficient and varies from region to region (Fig. 7). The average water use efficiency is about $47 \%$, and efficiency is considerably less in South China with relatively abundant water resources. Flood irrigation is still the predominant irrigation method. Therefore, there is plenty of room for improvement in water use efficiency (Wang, 2010). For example, Anhui (AH) and Fujian (FJ) had the highest IRs during 1961-2000, and their IRs are estimated to increase most in the future. Tibet (XZ), Sichuan (SC) and Gansu (GS) had low IRs during 1961-2000, but their relative IR increases are estimated to be almost the largest in the future. The irrigation water use efficiencies of each of these regions are lower than the national average. Improving the irrigation water use efficiency can certainly help those regions mitigate water stress owing to the IR increase. Methods for improving water use efficiency include regulating transpiration efficiency, enhancing soil water utilization efficiency, reducing soil evaporation ( $\mathrm{Li}$ et al., 2008), optimizing irrigation scheduling (Wang et al., 2001), developing water saving irrigation (Gao et al., 2002; Li, 2006; Zhang et al., 2006), and investing in water infrastructure, irrigation systems and irrigation equipment .

Water distribution is uneven both temporally and spatially. The Chinese government has set up the South-to-North Water Diversion Project in an attempt to transfer the water from the wet South China to the dry North China. The benefits and disadvantages of this project are disputed, however (Wang and Ma, 1999; Wang et al., 2009; Zhang, 2009). In the future, the Chinese government will keep investing in hydraulic projects, but more attention should be paid to the comprehensive assessment of the profits and costs - especially the potential ecological costs — of such projects (Yin and Yang, 2011). Meanwhile, adjusting planting and harvest dates based on temporal climate change such as Pr might be a useful adaptation to uneven temporal water distribution.

Currently, farmers have little incentive to water saving, and not all of them realize that water is a nonrenewable resource (Wang et al., 2006; Bluemling et al., 2010). They also lack the knowledge to optimize the irrigation schedule and apply water saving measures. Therefore, the Chinese government needs to create organizations to help farmers develop water saving technologies and enhance their consciousness of water saving. The water price reform is also helpful for controlling water consumption, but it must be implemented in cooperation with other water management policies.

In addition, developing drought-resistant crops, planting new strains of genetically modified crops and water efficient cultivars (Hu et al., 2006; Zhang et al., 2010), shifting sowing dates, and adjusting crop distribution and structure also help to reduce water consumption and keep agricultural production high 

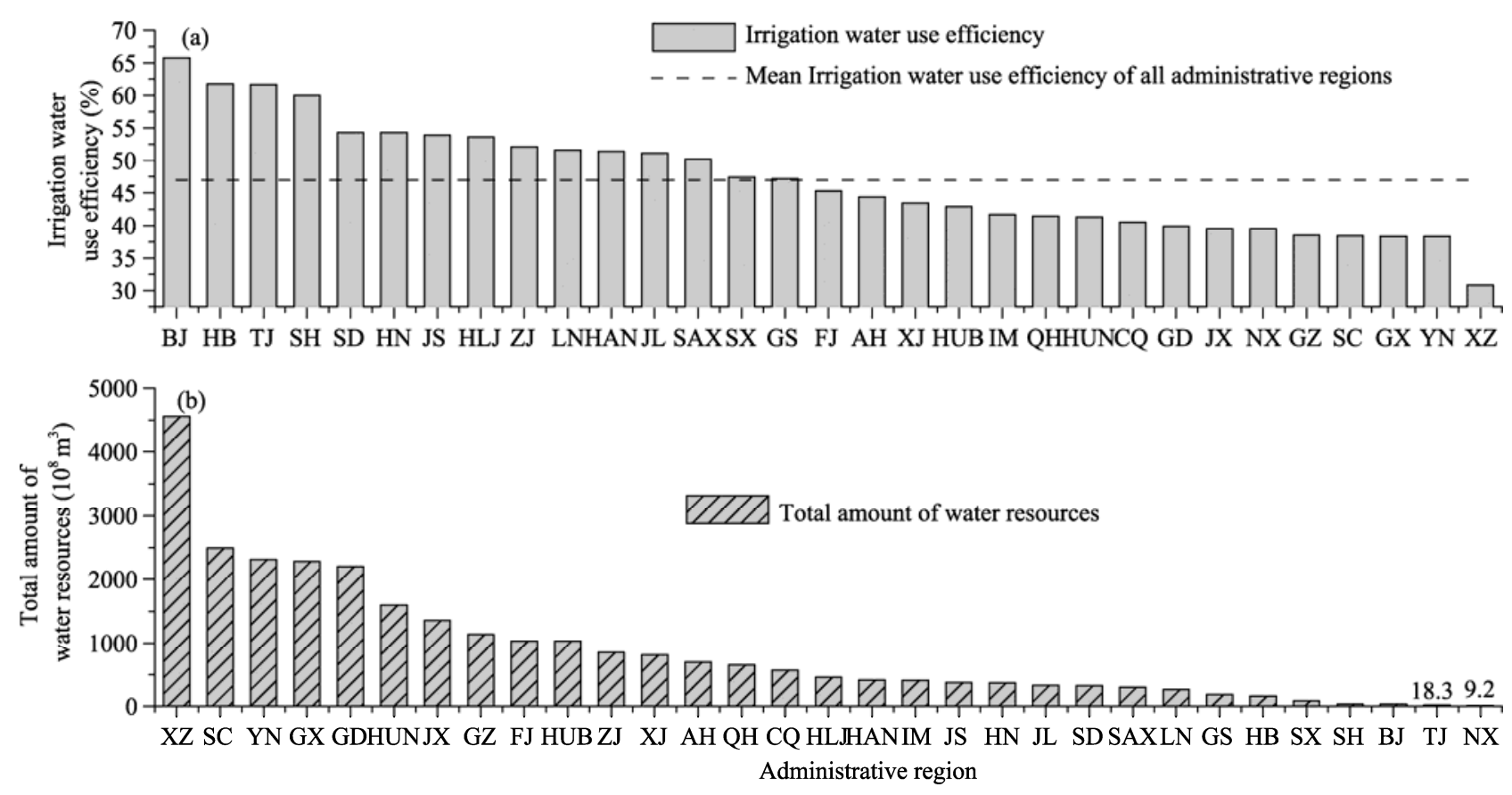

Fig. 7 Irrigation water use efficiency across mainland China. (Note: The data for the total water resources were obtained from the China Statistical Yearbook 2009; the data for the irrigation water use efficiency were derived from the National Irrigation Water Use Efficiency Measure and Analysis Report 2006. Beijing (BJ); Tianjin (TJ); Hebei (HB); Shanxi (SX); Inner Mongolia (IM); Liaoning (LN); Jilin (JL); Heilongjiang (HLJ); Shanghai (SH); Jiangsu (JS); Zhejiang (ZJ); Anhui (AH); Fujian (FJ); Jiangxi (JX); Shandong (SD); Henan (HN); Hubei (HUB); Hunan (HUN); Guangdong (GD); Guangxi (GX); Hainan (HAN); Chongqing (CQ); Sichuan (SC); Guizhou (GZ); Yunnan (YN); Tibet (XZ); Shaanxi (SAX); Gansu (GS); Qinghai (QH); Ningxia (NX); Xinjiang (XJ).

(Li et al., 2010; Tao and Zhang, 2010; Wang et al., 2010; Wang et al., 2011). For example, in our estimation, the IR of middle rice will increase most in future, so it might be helpful to mitigate water stress while maintaining rice output by giving up some middle rice and planning more early and late rice.

\subsection{Limitations of our study}

Climate change can directly influence the IR of a cropland. For example, warmer temperatures and less precipitation can increase the IRs. On the other hand, climate change can indirectly affect the IRs by influencing crop distribution, planting structure, multiple cropping index, duration of the growth season and the area of irrigated farmland. In this study, we calculated the IRs of three main crops planted in China based on daily data from eight models in IPCC 4. To reduce the uncertainties, we performed the analyses by averaging the IR estimations calculated from the eight models. Moreover, we performed both spatial and temporal analyses for 2046-2065 using three scenarios to obtain an overall impression of future changes in climate and IRs in the croplands of China. However, the present study has a number of limitations.

First, we assumed that cropland area and growing season would remain unmodified by climate change (Thomas, 2008). Considering the future higher temperatures, however, both cropland area and sowing date might change. Increased $\mathrm{CO}_{2}$ concentrations in the future may also directly affect crop transpiration by decreasing bulk stomatal conductance and the evapotranspiration generated by crops (Gornall et al., 2010). These considerations are beyond the scope of our current study.

Second, we estimated IR simply from the difference between evapotranspiration and Peff. IR is impacted not only by climate factors (T, DSR and Pr) but also by other parameters such as the water-holding capacity of soil. Information on the soil type (Allen et al., 1998), texture and moisture are difficult to collect. In the present study, we ignored the differences in IRs owing to the water-holding capacities of the soil. 
Third, we calculated the net IRs, not the actual IRs. Net irrigation water requirement is the quantity of water necessary for crop growth. It depends on the cropping pattern and climate. Actual IR is the total water requirement of the procedure of transferring irrigation water from water resources (rivers, reservoirs and aquifers) to fields. It is the quantity of water to be applied in reality, taking into account the water losses. Actual IR, but not net IR, can reflect actual agricultural water requirements and water stress. For calculating actual IR, more information is needed, especially irrigation water use efficiency. However, changes in irrigation water use efficiency differ from area to area owing to variations in financial investments by local governments and the current developmental level and improvement potential of irrigation systems. There are no records on the irrigation water use efficiency for each year in China. Furthermore, it is impossible to predict water use efficiency for future time intervals.

\section{Conclusions}

This study utilized eight global climate models to analyze changes in IRs and agricultural drought in response to rising greenhouse gas concentrations in China. The analysis was based on multiple-model averages of climate differences between 1961-2000 data and simulations from three scenarios. The results are as follows:

Northeast China, the North China Plain and the Yarlung Tsangpo River Valley area in southeastern Tibet were estimated to be becoming wetter in the future, whereas Southeast and Northwest China, especially the Junggar and the Tarim basins in Xinjiang Uygur autonomous region will be drier. DSR will decrease, whereas T, PET, Pr, Peff and IRs will increase. DSR will undergo the largest decrease in spring and the smallest decrease in summer. $\mathrm{T}$ will experience a huge increase in winter, and PET will increase the most in summer. P will increase the most in summer, whereas Peff will increase the most in spring. These trends indicate that extreme rain will occur more frequently in future summers. Overall, IRs will increase the most in summer (June-August), especially in July, and the least in autumn
(September-November). The IRs of the three crops examined will increase in the future under all three scenarios. Basically, middle rice will contribute the maximum to the total IR increase.

High-risk areas that will experience large increases in IRs are in Northwest China (the Tarim and Junggar basins of the Xinjiang Uygur autonomous region, the Hexi Corridor of Gansu province and the Guanzhong Plain of Shaanxi province), Southeast China (especially Fujian province) and Southwest China (Yarlung Tsangpo River Valley area in Tibet and the Sichuan Basin).

\section{Acknowledgements}

This study is supported by the Specialized Research Fund for the Doctoral Program of Higher Education of China (20130003120041), State Key Laboratory of Earth Surface Processes and Resource Ecology (2013-RC-04) and the Fundamental Research Funds for the Central Universities (2013YB74).

\section{References}

Allen R G, Pereira L S, Raes D, et al. 1998. Crop evapotranspiration: guidelines for computing crop water requirements. Rome: Food and Agriculture Organization of the United Nations.

Bluemling B, Yang H, Mosler H J. 2010. Adoption of agricultural water conservation practices - a question of individual or collective behaviour? The case of the North China Plain. Outlook on Agriculture, 39(1): 7-16.

Cai X M. 2005. Risk in irrigation water supply and the effects on food production. Journal of the American Water Resources Association, 41(3): 679-692.

Chavas D R, Izaurralde R C, Thomson A M, et al. 2009. Long-term climate change impacts on agricultural productivity in eastern China. Agricultural and Forest Meteorology, 149(6-7): 1118-1128.

Chen H P, Sun J Q. 2009. How the "Best" Models Project the Future Precipitation Change in China. Advances in Atmospheric Sciences, 26(4): 773-782.

Chen Y, Zhang D Q, Sun Y B, et al. 2005. Water demand management: a case study of the Heihe River Basin in China. Physics and Chemistry of the Earth, 30(6-7): 408-419.

Doll P. 2002. Impact of climate change and variability on irrigation requirements: a global perspective. Climatic Change, 54(3): 269-293.

Fang C L, Bao C, Huang J C. 2007. Management implications to water resources constraint force on socio-economic system in rapid urbanization: a case study of the Hexi Corridor, NW China. Water Resources Management, 21(9): 1613-1633.

FAO. 1992. CROPWAT-A Computer Program for Irrigation Planning and Management. FAO Irrigation and Drainage Paper No.46, Foodand Agriculture Organization, Rome. 
Gao Q Z, Du H L, Zu R P. 2002. The balance between supply and demand of water resources and the water-saving potential for agriculture in the Hexi Corridor. Chinese Geographical Science, 12(1): 23-29.

Gornall J, Betts R, Burke E, et al. 2010. Implications of climate change for agricultural productivity in the early twenty-first century. Philosophical Transactions of the Royal Society B: Biological Sciences, 365(1554): 2973-2989.

Guo R P, Lin Z H, Mo X G, et al. 2010. Responses of crop yield and water use efficiency to climate change in the North China Plain. Agricultural Water Management, 97(8): 1185-1194.

Hargreaves G H, Samani Z A. 1982. Estimating potential evapotranspiration. Journal of Irrigation Drainage Division, Proceeding of American Society of Civil Engineers, 108: 225-230.

Hu Y C, Shao H B, Chu L Y, et al. 2006. Relationship between water use efficiency (WUE) and production of different wheat genotypes at soil water deficit. Colloids and Surfaces B-Biointerfaces, 53(2): 271-277.

Huang Q Q, Rozelle S, Lohmar B, et al. 2006. Irrigation, agricultural performance and poverty reduction in China. Food Policy, 31(1): $30-52$.

Kharin V V, Zwiers F W, Zhang X B, et al. 2007. Changes in temperature and precipitation extremes in the IPCC ensemble of global coupled model simulations. Journal of Climate, 20(8): 1419-1444.

Kitoh A, Hosaka M, Adachi Y, et al. 2005. Future projections of precipitation characteristics in East Asia simulated by the MRI CGCM2. Advances in Atmospheric Sciences, 22(4): 467-478.

Li S, Kang S H, Li F S, et al. 2008. Evapotranspiration and crop coefficient of spring maize with plastic mulch using eddy covariance in northwest China. Agricultural Water Management, 95(11): 1214-1222.

Li S A, Wheeler T, Challinor A, et al. 2010. Simulating the impacts of global warming on wheat in China using a large area crop model. Acta Meteorologica Sinica, 24(1): 123-135. (in Chinese)

Li Y H. 2006. Water-saving irrigation in China. Irrigation and Drainage, 55(3): 327-336.

Lin E D, Xiong W, Ju H, et al. 2005. Climate change impacts on crop yield and quality with $\mathrm{CO}_{2}$ fertilization in China. Philosophical Transactions of the Royal Society B-Biological Sciences, 360(1463): 2149-2154.

Liu H, Li X B, Fischer G, et al. 2004. Study on the impacts of climate change on China's agriculture. Climatic Change, 65(1-2): 125-148.

Liu S X, Mo X G, Lin Z H, et al. 2010. Crop yield responses to climate change in the Huang-Huai-Hai Plain of China. Agricultural Water Management, 97(8): 1195-1209.

Mo X G, Liu S X, Lin Z H, et al. 2009. Regional crop yield, water consumption and water use efficiency and their responses to climate change in the North China Plain. Agriculture Ecosystems \& Environment, 134(1-2): 67-78.

NSBC (National Statistical Bureau of China). 2010. China Statistical Yearbook 2009. Beijing: China Statistical Press. (in Chinese)

Pachauri R K, Reisinger A. 2007. Climate Change 2007: Synthesis Report. Geneva, Switzerland: IPCC.

Rockstrom J, Falkenmark M, Karlberg L, et al. 2009. Future water availability for global food production: the potential of green water for increasing resilience to global change. Water Resources Research, 45: 16.

Rosenzweig C, Strzepek K M, Major D C, et al. 2004. Water resources for agriculture in a changing climate: international case studies. Global Environmental Change-Human and Policy Dimensions, 14(4): 345-360.

Sheffield J, Wood E F. 2008. Projected changes in drought occurrence under future global warming from multi-model, multi-scenario, IPCC AR4 simulations. Climate Dynamics, 31(1): 79-105.

Siebert S, Döll P. 2008. The Global Crop Water Model (GCWM): documentation and first results for irrigated crops. Frankfurt am Main, Germany, Institute of Physical Geography, University of Frankfurt.

Tao F, Yokozawa M, Hayashi Y, et al. 2003. Future climate change, the agricultural water cycle, and agricultural production in China. Agriculture Ecosystems \& Environment, 95(1): 203-215.

Tao F, Hayashi Y, Zhang Z, et al. 2008. Global warming, rice production, and water use in China: developing a probabilistic assessment. Agricultural and Forest Meteorology, 148(1): 94-110.

Tao F L, Zhang Z, Liu J Y, et al. 2009. Modelling the impacts of weather and climate variability on crop productivity over a large area: a new super-ensemble-based probabilistic projection. Agricultural and Forest Meteorology, 149(8): 1266-1278.

Tao F L, Zhang Z. 2010. Adaptation of maize production to climate change in North China Plain: quantify the relative contributions of adaptation options. European Journal of Agronomy, 33(2): 103-116.

Tao F L, Zhang Z. 2011. Impacts of climate change as a function of global mean temperature: maize productivity and water use in China. Climatic Change, 105(3-4): 409-432.

Thomas A. 2008. Agricultural irrigation demand under present and future climate scenarios in China. Global and Planetary Change, 60(3-4): 306-326.

UNEP. 1997. World Atlas of Desertification ( $2^{\text {nd }}$ ed.). London: UNEP.

Wang H X, Zhang L, Dawes W R, et al. 2001. Improving water use efficiency of irrigated crops in the North China Plain-measurements and modelling. Agricultural Water Management, 48(2): 151-167.

Wang J X, Xu Z G, Huang J K, et al. 2006. Incentives to managers or participation of farmers in China's irrigation systems: which matters most for water savings, farmer income, and poverty? Agricultural Economics, 34(3): 315-330.

Wang L S, Ma C. 1999. A study on the environmental geology of the Middle Route Project of the South-North water transfer. Engineering Geology, 51(3): 153-165.

Wang M, Li Y P, Ye W, et al. 2011. Effects of climate change on maize production, and potential adaptation measures: a case study in Jilin Province, China. Climate Research, 46(3): 223-242.

Wang W, Dai J R, Liang Y S, et al. 2009. Impact of the South-to-North Water Diversion Project on the transmission of Schistosoma japonicum in China. Annals of Tropical Medicine and Parasitology, 103(1): 17-29.

Wang X Q, Gao Q Z. 2002. Sustainable development and management of water resources in the Hei River basin of north-west China. International Journal of Water Resources Development, 18(2): 335-352. 
Wang X Y. 2010. Irrigation water use efficiency of farmers and its determinants: evidence from a survey in Northwestern China. Agricultural Sciences in China, 9(9): 1326-1337.

Wang Y B, Wu P T, Zhao X N, et al. 2010. The optimization for crop planning and some advances for water-saving crop planning in the semiarid Loess Plateau of China. Journal of Agronomy and Crop Science, 196(1): 55-65.

Wang Y Q. 2004. Regional climate modeling: progress, challenges, and prospects. Journal of the Meteorological Society of Japan, 82(6): 1599-1628.

Wei Y C, Miao H, Ouyang Z Y. 2008. Environmental water requirements and sustainable water resource management in the Haihe River Basin of North China. International Journal of Sustainable Development and World Ecology, 15(2): 113-121.

Wu P T, Jin J M, Zhao X N. 2010. Impact of climate change and irrigation technology advancement on agricultural water use in China. Climatic Change, 100(3-4): 797-805.

Xiong W, Lin E D, Ju H, et al. 2007a. Climate change and critical thresholds in China's food security. Climatic Change, 81(2): 205-221.

Xiong W, Matthews R, Holman I, et al. 2007b. Modelling China's potential maize production at regional scale under climate change.
Climatic Change, 85(3-4): 433-451.

Xiong W, Conway D, Lin E D, et al. 2009. Potential impacts of climate change and climate variability on China's rice yield and production. Climate Research, 40(1): 23-35.

Yao F M, Xu Y L, Lin E D, et al. 2007. Assessing the impacts of climate change on rice yields in the main rice areas of China. Climatic Change, 80(3-4): 395-409.

Yin X A, Yang Z F. 2011. Development of a coupled reservoir operation and water diversion model: balancing human and environmental flow requirements. Ecological Modelling, 222(2): 224-231.

Zhang B C, Li F M, Huang G B, et al. 2006. Yield performance of spring wheat improved by regulated deficit irrigation in an and area. Agricultural Water Management, 79(1): 28-42.

Zhang Q F. 2009. The South-to-North Water Transfer Project of China: environmental implications and monitoring strategy. Journal of the American Water Resources Association, 45(5): 1238-1247.

Zhang X Y, Chen S Y, Sun H Y, et al. 2010. Water use efficiency and associated traits in winter wheat cultivars in the North China Plain. Agricultural Water Management, 97(8): 1117-1125.

Zhang Y, Xu Y L, Dong W J, et al. 2006. A future climate scenario of regional changes in extreme climate events over China using the PRECIS climate model. Geophysical Research Letters, 33(24): 6. 